\title{
Effect of Inspiratory Muscle Training on Weaning Success in Critically III Intubated Patients
}

\author{
Samária Cader, Rodrigo Vale and Estélio Dantas \\ Human Motricity Biosciences Laboratory of the Federal University of Rio de Janeiro State, \\ Labimh/Unirio, \\ Brazil
}

\section{Introduction}

Approximately $50 \%$ of patients hospitalized in an intensive therapy center (ITC) rely on mechanical ventilation (MV) for an indeterminate time, depending on the reason for intubation. Once the triggering cause of acute respiratory failure (ARF) is stabilized, patients are weaned from mechanical ventilation, which is followed by extubation (Scheinhorn, Chao, \& Stearn-Hassenpflug, 2000).

Weaning from MV is the gradual removal of the ventilatory prosthesis, a different process to extubation, which involves removing the endotracheal tube (MacIntyre et al., 2001). The best moment to start weaning depends on multiple factors. Premature exhubation puts the patient at risk of reintubation and airway trauma. However, prolonged weaning exposes individuals to risk of hospital infection and increases hospitalization costs (C. D. Epstein et al., 2002).

Although there are a wide range of weaning protocols, there is still no consensus on which one is the best (Butler et al., 1999). In addition to this diversity, there are also so-called predictors for ventilatory interruption and successful extubation (Chatila et al., 1996; Khamiees et al., 2001; Meade et al., 2001). Among these markers are: (a) rapid shallow breathing index or Tobin index (Li et al., 2000; Meade, et al., 2001) (b) maximal inspiratory pressure (MIP) (A. Bruton, 2002; El-Khatib et al., 1996); and (c) maximal expiratory pressure (MEP) (Salam et al., 2004) .

The Tobin index is the most commonly used predictor to indicate the possibility of weaning success (Frutos-Vivar et al., 2006; Meade, et al., 2001; Stroetz \& Hubmayr, 1995), although some studies did not find a significant response with respect to effective extubation (Conti et al., 2004).

Even though these and other predictors are well controlled, during the weaning process some individuals experience spontaneous breathing difficulties, thereby prolonging dependence on the mechanical ventilator (Chao \& Scheinhorn, 1998).

One of the main causes of unsuccesful weaning and extubation is failure of the respiratory muscle pump, mainly inspiratory muscles (diaphragm, external intercostals, scalene, 
pectoral and sterno-cleido-occipito-mastoid) (X. Capdevila et al., 1998; Cluzel et al., 2000; A. D. Martin et al., 2002; S T Venkataraman et al., 2000), which leads to prolonged dependence on MV (Vassilakopoulos \& Petrof, 2004). Muscle failure is due to two factors: (1) increase in workload to which the muscle is submitted owing to carbon dioxide (CO2) accumulation; greater airway resistance; reduced pulmonary compliance; increase in dead space or in respiratory stimulus; (2) lower neuromuscular capacity caused by phrenic nerve dysfunction; neuromuscular disorder due to dependence on MV and reduced respiratory muscle strength or endurance (Chao \& Scheinhorn, 1998; Meade, et al., 2001; Spitzer et al., 1992)

This reduction in muscle strength results from systemic problems, such as kidney failure, poor glycemic control, history of prolonged corticosteroid use, sepsis, electrolytic and mineral abnormalities, in addition to the use of neuromuscular blockers,widely administered in cases of patients who are not successfully sedated (A. A. Bruton et al., 2002). To delimit this muscle weakness, the most observed symptom is dyspnea (McConnell \& Romer, 2004; Nield, 1999), and the most reliable parameter for measuring this variable (inspiratory muscle strength) is MIP (Clanton et al., 2002; Green et al., 2002).

To prevent dyspnea from interfering in the weaning process and successful extubation, some studies suggest the need to increase inspiratory muscle strength (Caruso et al., 2005; Chang et al., 2005).

The effectiveness of inspiratory muscle strengthening has been reported in apparently healthy elderly (S A Cader et al., 2007), athletes (Inbar et al., 2000) and diverse pathologies, such as: restrictive pulmonary disease (Chatham, 2000); myotonic muscular dystrophy (de Freitas Fregonezi et al., 2006); Duchenne muscular dystrophy (Topin et al., 2002); cystic fibrosis (Enright et al., 2004), chronic obstructive pulmonary disease (COPD) (Sturdy et al., 2003), congestive heart failure (CAD) (Laoutaris et al., 2004), asthma (Weiner et al., 2002), sarcoidosis (Brancaleone et al., 2004), cancer (Bruera et al., 2000), spinal cord injury (SCI) (Liaw et al., 2000), tetraplegia (Uijl et al., 1999), ankylosing spondylitis (Van der Esch et al., 2004), osteoporosis (Cimen et al., 2003) and multiple sclerosis (Klefbeck et al., 2003). However, there are no studies on inspiratory muscle strengthening in critically ill intubated patients, hospitalized in an ITC.

One of the inspiratory muscle training (IMT) techniques used in intubated patients is a reduction of pressure support mechanical ventilation. However, no studies are available that have investigated on the threshold IMT instrument.

The present study assumes that, when aiming for strength, IMT is suitable for patients with weak inspiratory muscles, since it exhibits the same principles as limb strength training, namely: (1) as with skeletal muscles, respiratory muscle weakness occurs with disuse; (2) with increased demand on the respiratory system, patients are unable to maintain spontaneous breathing for long periods; and (3) perception of respiratory effort is inversely proportional to inspiratory muscle strength, that is, the lower the inspiratory muscle strength, the higher the effort perception (A. A. Bruton, et al., 2002; Campbell et al.Gandevia, Killian et al., 1980; Cluzel, et al., 2000; Yue \& Cole, 1992).

Although IMT performed over a short time period is not sufficient to cause significant changes in distribution of muscle fiber types or in the transverse muscle section, a number 
of mechanisms are evident: changes in the motor program and excitability of the neuromuscular system; neural adaptation, including a decrease in coactivation in the antagonist muscle group, a synchronic increase in the motor unit and a more efficient motor program (Carolan \& Cafarelli, 1992; McComas, 1994; Milner-Brown et al., 1975; Sale, 1988; Yue \& Cole, 1992).

Prior explanation is needed regarding mechanical ventilation and its ventilatory modes, weaning and its predictors, as well as inspiratory muscle strengthening itself in order to better understand the proposal of this chapter.

\section{Mechanical ventilation}

The main reason for patient admittance to the ICU is the need to install MV so as to reduce respiratory work and offer adequate oxygen support (Tobin, 2001). Esteban et al. (Esteban et al., 2000) conducted a study in eight countries with a total of 1638 patients. Indications for MV included the following: acute respiratory failure (ARF - 66\%); coma (15\%); COPD (13\%); and neuromuscular disorders (5\%). ARF primarily involved pneumonia, sepsis, surgical complications and trauma.

$\mathrm{ARF}$ is defined as the failure of lungs and the respiratory pump to maintain adequate gas exchange between oxygen $(\mathrm{O} 2)$ and $\mathrm{CO} 2$. Hypoxemic ARF (type 1) consists of intrapulmonary impairment resulting in alveolar collapse, which leads to intrapulmonary shunting and inadequate arterial oxygenation. Hypercapnic ARF (type 2) is an extrapulmonary injury, resulting in the inability of the respiratory pump to sustain sufficient alveolar ventilation to eliminate metabolically produced CO2 (Manthous et al., 1998). In this respect, the mechanical ventilator can substitute the respiratory pump until the initial disorder triggering ARF has been suitably reversed (Esteban et al., 1997; S. T. Venkataraman et al., 2000).

Chronic dependence on the mechanical ventilator is not only the main medical problem (N Ambrosino, 2005), but also an extremely uncomfortable state with important social implications (Appendini et al., 1996). Furthermore, MV is associated to greater complications, such as infection, barotrauma, cardiovascular impairment, tracheal lesion, oxygen toxicity and MV-induced pulmonary injury (Vassilakopoulos \& Petrof, 2004). Some investigators have sought to determine the pathological mechanisms that lead to unsuccessful weaning in patients chronically dependent on MV (Appendini, et al., 1996).

\subsection{Conventional ventilation modes}

All patients using ventilatory prostheses are ventilated by the following modes: assist/control ( volume or pressure) and synchronized intermittent mandatory ventilation (SIMV) with pure pressure suport (PS) or pressure suport ventilation (PSV) (Esteban, Anzueto, et al., 2000). Choosing the ideal ventilation mode and adequate parameters is essential to reducing respiratory muscle overload, since there must be patient-ventilator synchronism (Tobin et al., 2001).

In the assist/control mode (the most widely used), the ventilator releases a previously established current volume (volume-controlled ventilation -VCV) or inspiratory pressure 
(pressure-controlled volume - PCV) to the patient, in the presence of patient effort (assist mode) or not (control mode) (Rose \& Ed, 2006). Even though VCV guarantees adequate current volume, it does not limit peak pressure, which may result in altered compliance and resistance, in addition to provoking barotrauma. However, although PCV does not ensure constant current volume, it reduces the risk of pulmonary injury by determining and maintaining airway pressure and gas exchange, decreasing respiratory work and preventing hyperdistension of healthy alveoles (Esteban, Alia, et al., 2000).

SIMV with PS was introduced to provide a gradual level of assistance. This mode intersperses mandatory cycles, with pre-established respiratory frequency and current volume, as well as spontaneous cycles, in which respiratory frequency and current volume are peculiar to the patients themselves. The spontaneous cycle offers pressure support for the patient to generate adequate current volume (Leung et al. 1997).

PSV and SIMV with PS also offer ventilatory assistance, which is gradually lowered, but consists only of spontaneous cycles. PS is reduced according to the patient's respiratory frequency and current volume (Esteban, Anzueto, et al., 2000). PSV, characterized by low pressure values $(7-8 \mathrm{cmH} 2 \mathrm{O})$, has been used as a weaning protocol. Kuhlen et al. (Kuhlen et al., 2003) observed that among T-piece, automatic tube compensation and PSV, the latter provided the least ventilatory overload in patients submitted to weaning, about to be disconnected from the ventilatory prosthesis. Similar data were recorded by Ezingeard et al. (Ezingeard et al., 2006). However, Haberthur et al. (2002) found no significant differences among the 3 protocols.

In a randomized prospective study, Matic et al. (Matic et al., 2007) observed that PSV weaning was more successful than theT-piece device in the extubation process $(p<0.001)$ and the group submitted to T-piece also spent more time on MV and in the ICU $(p<0.001)$, when compared with the PSV group.

New ventilation modes are increasingly being introduced. Recent proposals include increasing respiratory muscle rest; preventing deconditioning; improving gas exchange; avoiding pulmonary lesion and increasing patient-ventilator coordination (Tobin, 2001). Within these modalities are volume assured pressure support (VAPS), bilevel positive airway pressure (BiPAP) and airway pressure release ventilation (APRV) (Rose \& Ed, 2006).

\section{Weaning and extubation}

Difficult-to-wean patients account for 20-25\% of those mechanically ventilated (Vassilakopoulos \& Petrof, 2004), and an even higher percentage of individuals with COPD (Matic, et al., 2007). Weaning commences with reduced ventilatory support, depending on the degree to which patients can ventilate themselves adequately, culminating with their being withdrawn from MV; extubation consists of removing the endotracheal tube (Meade, et al., 2001; Robriquet et al., 2006).

Weaning failure is a result of complications in the central respiratory stimulus or, more commonly, due to neuromuscular abnormalities, such as muscle fatigue and altered pulmonary mechanisms or gas exchange (Meade, et al., 2001). The ventilatory pattern of 
patients that are not successfully weaned is similar to that observed during AFR (Del Rosario et al., 1997). Thus, some investigators recommend inspiratory muscle strengthening to reduce respiratory muscle fatigue (Chang, Boots, Brown, et al., 2005) and facilitate weaning from MV (Del Rosario et al., 1997).

Extubation failure occurs when there is a need to reinstitute ventilatory support between 24 and 48 hours after tube removal. Rothaar \& Epstein (Rothaar \& Epstein, 2003) sumarize the main causes for extubation failure can be seen in chart 1 .

Although the ideal weaning procedure has yet to be established, the literature reports three main techniques: SIMV, T-piece and PSV. Other less widely used methods are automatic tube compensation, continuous positive airway pressure (CPAP) and bilevel positive airway pressure - BiPAP (Esteban et al., 1995; Haberthur, et al., 2002).

MV must be interrupted as soon as the patient is capable of adequately sustaining spontaneous breathing and gas exchange (Farias et al., 2002). However, the benefits of rapid release from MV must be weighed against the risks of weaning and premature extubation (Meade, et al., 2001), since these have been associated to increased hospital costs, mortality, length of ICU stay and need for tracheostomy (Esteban, et al., 1997; Rothaar \& Epstein, 2003), in addition to generating new trauma in the airways due to reintubation (Noizet et al., 2005).

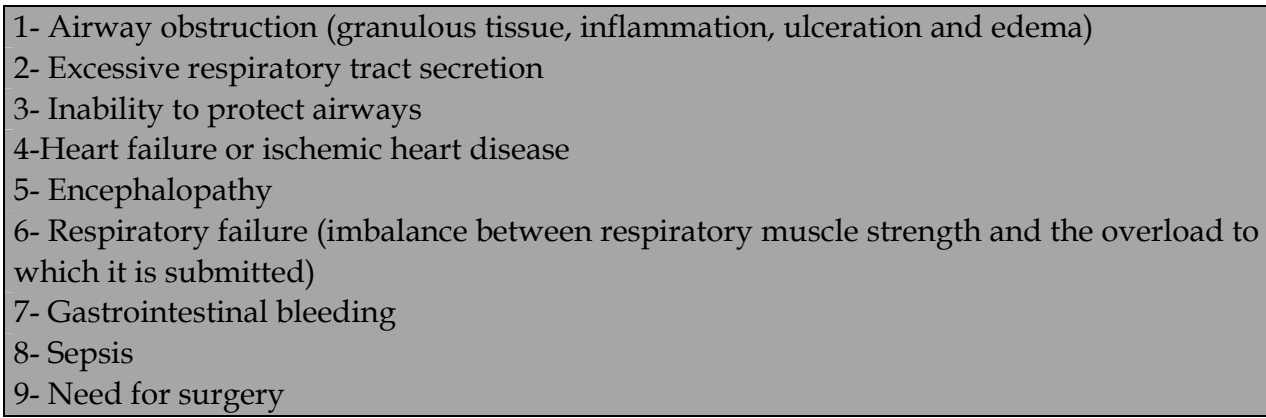

Thus, the complex decision to extubate requires an adequate assessment of predictor accuracy in this process (S. K. Epstein, 2002).

Chart 1. Main causes of extubation failure.

\subsection{Weaning and extubation predictors (Tobin index, MIP and MEP)}

Several indices have been proposed to predict weaning from MV. These reflect respiratory mechanics, pulmonary gas exchange, respiratory control and respirastory muscle function (chart 2) (Alvisi et al., 2000; Hoo \& Park, 2002; Meade, et al., 2001; Rothaar \& Epstein, 2003). Despite the wide range of predictors, Vallverdú et al. (Vallverdu et al., 1998) considered the Tobin index, MIP and MEP as good predictors. 


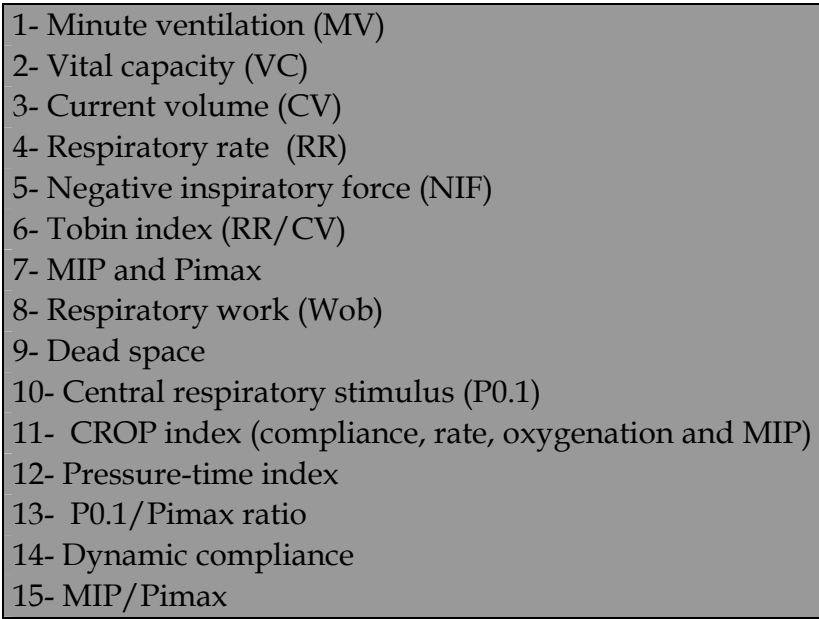

Chart 2. Diversity of weaning and extubation predictors.

A common finding in patients who were not successfully weaned is a high Tobin index score (RR/CV, in liters). It is measured with the patient disconnected from MV, where minute volume is verified during a 1-minute period (Goldstone, 2002). Yang and Tobin (Yang \& Tobin, 1991) observed that this index has a sensitivity of 0.97 and a specificity of 0.64 .

Thus, the Tobin index is the most widely accepted of the weaning indices. However, it does not consider ventilatory force or endurance, important requirements for successful weaning (Vassilakopoulos \& Petrof, 2004).

Although the cause of weak respiratory muscles is not entirely known, it is suggested that electrolytic disorders (hypophophatemia and hypomagnesemia), the use of certain medications (curarizing agents) and malnutrition, combined with muscle disuse, have contributed to the occurrence of this phenomenon. The atrophy process is rapid, occurring from 7 to 10 days after a reduction in maximum diaphragmatic pressure of 50\% (Anzueto et al., 1997).

MIP is the index used to measure inspiratory muscle strength (Volianitis et al., 2001). Although there is a conventional way to check this variable (Green, et al., 2002), Marini, Smith and Lamb (Marini et al., 1986) suggest a protocol that does not require patient collaboration. Some studies applying it as a predictor observed a significant difference $(\mathrm{p}<0.05)$ between patients who were successfully weaned (higher values) and those who were not (A. Bruton, 2002; C. D. Epstein, et al., 2002). Using a cutoff point of $-17 \mathrm{cmH} 2 \mathrm{O}$, Conti et al. (Conti, et al., 2004) found a sensitivity of 0.95 , specificity of 0.42 and accuracy of 0.71 .

For an effective cough, deep inspiration and expiratory force are important, since they generate high thoracic-abdominal pressure. Based on this cough mechanism, several assisted cough techniques were developed for individuals with respiratory muscle 
weakness. Although expiratory muscle strength is essential for an effective cough, inspiratory muscle strength is equally important in the inspiratory phase of a cough, capable of generating an ideal pulmonary volume (Jaeger et al., 1993). Nevertheless, there are few studies that correlate cough capacity with inspiratory muscle strength (Kang et al., 2006).

Chart 3 demonstrates the variability of MIP and Tobin index thresholds, as predictors of successful weaning and/or extubation.

\begin{tabular}{|c|c|c|}
\hline PREDICTORS & VALUES & REFERENCES \\
\hline \multirow{15}{*}{ Tobin index } & $60 \mathrm{ipm} / 1$ & X. J. Capdevila et al.(1995) \\
\hline & $96 \mathrm{ipm} / 1$ & Gandia \& Blanco (1992) \\
\hline & $100 \mathrm{ipm} / 1$ & Vallverdu et al.(1998) \\
\hline & $100 \mathrm{ipm} / 1$ & Yang (1993) \\
\hline & $100 \mathrm{ipm} / 1$ & S. K. Epstein \& Ciubotaru (1996) \\
\hline & $100 \mathrm{ipm} / 1$ & S. K. Epstein (1995) \\
\hline & $100 \mathrm{ipm} / 1$ & Afessa et al. (1999) \\
\hline & $100 \mathrm{ipm} / 1$ & Del Rosario et al.(1997) \\
\hline & $100 \mathrm{ipm} / 1$ & Dojat et al. (1996) \\
\hline & $100 \mathrm{ipm} / 1$ & Chatila et al. (1996) \\
\hline & $100 \mathrm{ipm} / 1$ & Leitch et al.(1996) \\
\hline & $105 \mathrm{ipm} / 1$ & Krieger et al. (1997) \\
\hline & $105 \mathrm{ipm} / 1$ & Mergoni et al. (1996) \\
\hline & $105 \mathrm{ipm} / 1$ & Lee, Hui, \& Chang (1994) \\
\hline & $105 \mathrm{ipm} / 1$ & Yang \& Tobin ( 1991) \\
\hline \multirow{7}{*}{ MIP } & $15 \mathrm{cmH} 2 \mathrm{O}$ & Yang (Yang, 1993) \\
\hline & $20 \mathrm{cmH} 2 \mathrm{O}$ & Del Rosario et al.( 1997) \\
\hline & $20 \mathrm{cmH} 2 \mathrm{O}$ & Krieger et al.(1997) \\
\hline & $20 \mathrm{cmH} 2 \mathrm{O}$ & Afessa et al.(1999) \\
\hline & $25 \mathrm{cmH} 2 \mathrm{O}$ & Manthous et al.(1998) \\
\hline & $25 \mathrm{cmH} 2 \mathrm{O}$ & Goldwasser (1998) \\
\hline & $30 \mathrm{cmH} 2 \mathrm{O}$ & Mergoni et al. (1996) \\
\hline
\end{tabular}

Chart 3. Variability of MIP and Tobin index values for successful weaning and/or extubation.

\section{Respiratory muscle training}

Malnutrition, detraining and disuse due to prolonged bedrest may induce severe skeletal muscle dysfunction. Combined with other factors, such as reduced oxygen support, metabolic acidosis, electrolytic alterations and endocrine disorders, muscle disuse may lead to muscle atrophy (N Ambrosino, 2005; A. A. Bruton, et al., 2002). Within these factors there is predominance of isolated corticosteriod action, potentialized by neuromuscular blocking agents, immobility and sepsis (Larsson et al., 2000). 
Respiratory muscles are skeletal muscles and, during prolonged mechanical ventilation (more than 48 hours), (A. Bruton, 2002; Chang, Boots, Brown, et al., 2005; Chelluri et al. 2002; Douglas et al. 2002) - inspiratory muscles move passively, favoring atrophy from disuse (Angus et al., 2005; A. A. Bruton, et al., 2002). The level of this strength reduction is related to duration of MV (Chang, Boots, Brown, et al., 2005; Powers et al., 2002; Sassoon, Caiozzo et al., 2002; Sprague \& Hopkins, 2003) and has been reported as one of the major determinants of weaning failure in patients receiving MV (N Ambrosino, 2005; Gayan-Ramirez \& Decramer, 2002). Anzueto et al. (Anzueto, et al., 1997) observed a transdiaphragmatic pressure reduction of $45 \%$ in rats after 11 days of controlled MV.

Thus, some studies described using IMT to increase inspiratory muscle effectiveness, in order to assist with difficult weaning. The main training techniques are: (a) endurance training using eucapnic hyperventilation (Aldrich \& Karpel, 1985; Aldrich et al., 1989; Aldrich \& Uhrlass, 1987; Belman, 1981); (b) threshold IMT strength training (A. D. Martin, et al., 2002; U. J. Martin et al., 2005; Sprague \& Hopkins, 2003) and (c) resistance training by reducing ventilatory prosthesis sensitivity (Caruso, et al., 2005). The literature also cites other less widely used IMT methods, such as the solenoid device and the weighted plunger (Bardsley et al., 1993; Johnson et al., 1996).

Inspiratory muscle endurance can be defined as sustained MIP (SMIP), which is the ability to maintain a simple contraction over a prolonged period of time. It is a dynamic maneuver, whereas MIP is considered static or quasi-static (A. A. Bruton, et al., 2002).

SMIP is measured from residual volume and the orifice must be occluded immediately at the onset of inspiration so as to generate negative intrathoracic pressure, which is verified on the gauge (Green, et al., 2002). Inspiration must last at least 3 seconds, with maximum force and time possible. This procedure is repeated three times, and the best result is used (Cimen, et al., 2003). However, it is not easy to reproduce in mechanically ventilated patients due to lack of understanding or even interaction with the examiner. As such, an alternative for this problem is the use of an expiratory unidirectional valve since it permits free expiration, progressively reaching a volume close to the residual value, whereas for inspiration the patient must exert an effort to generate sufficient negative pressure (Caruso et al., 1999; Marini, et al., 1986).

Several factors indicate an individual should be submitted to IMT, the primary one being a simple decrease in MIP. After MIP is measured, inspiratory muscle strengthening and conditioning can be initiated (S A Cader, 2006). However, a significant problem for the inspiratory muscle training program is the protocol used. Chart 4 illustrates the range of protocols, none of which are standardized because of different medical conditions.

Although IMT of patients under MV is of short duration, some studies report that muscle strength gain is due to neural adaptation (A. D. Martin, et al., 2002; Sprague \& Hopkins, 2003) rather than muscle hypertrophy. The following mechanisms emerge as a result of this adaptation: increased maximum voluntary contraction ability; decreased antagonist muscle coactivation; greater motor unit synchrony or a more efficient motor program (Carolan \& Cafarelli, 1992; McComas, 1994; Milner-Brown, et al., 1975; Sale, 1988; Yue \& Cole, 1992). However, further studies are needed given that the exact mechanism cannot be determined from these findings. 


\begin{tabular}{|c|c|c|}
\hline PROTOCOL & REFERENCES & PATHOLOGY \\
\hline $8 W / 3 X / 10^{\prime} / 20-60 \%$ & $\begin{array}{l}\text { Fregonezi et al.(Fregonezi, } \\
\text { Resqueti, Guell, Pradas, \& Casan, } \\
\text { 2005) }\end{array}$ & Miasthenia gravis \\
\hline $8 W / 3 X / 45^{* *} / 80 \%$ & Enright et al.(Enright, et al., 2004) & Cystic Fibrosis \\
\hline 10W/ 3X/ time?/ 60\% & $\begin{array}{l}\text { Laoutaris et al.(Laoutaris, et al., } \\
\text { 2004) }\end{array}$ & $\mathrm{CHF}$ \\
\hline $10 W /$ INT (2)/ 3s-10x/ 40-60\% & $\begin{array}{l}\text { Klefbeck \& Hamrah Nedjad } \\
\text { (Klefbeck \& Hamrah Nedjad, 2003) }\end{array}$ & Multiple Sclerosis \\
\hline $8 \mathrm{~W} / 3 \mathrm{X} / 20^{\prime}-2^{\prime}+1^{\prime} / 70 \%$ & Sturdy et al.(Sturdy, et al., 2003) & COPD \\
\hline $5 W / 5 X / 30 \prime / 40-50 \%$ & $\begin{array}{l}\text { Ramirez-Sarmiento et al. (Ramirez- } \\
\text { Sarmiento et al., 2002) }\end{array}$ & COPD \\
\hline $\begin{array}{l}12 \mathrm{~W} / 3 \mathrm{X}(2) / 5^{\prime} / 5-7 \% \text { de } \\
\text { increase every } 2 \mathrm{~S}\end{array}$ & $\begin{array}{l}\text { de Freitas Fregonezi, Resqueti, \& } \\
\text { Casan (de Freitas Fregonezi, et al., } \\
2006 \text { ) }\end{array}$ & $\begin{array}{l}\text { Myotonic muscular } \\
\text { dystrophy }\end{array}$ \\
\hline $24 W / 6 X / 30 \prime / 60-70 \%$ & $\begin{array}{l}\text { Sanchez Riera et al. (Sanchez Riera } \\
\text { et al., 2001) }\end{array}$ & COPD \\
\hline $6 \mathrm{~W} / 7 x(2) / 10^{\prime} / 30 \%$ & Topin et al. (Topin, et al., 2002) & $\begin{array}{l}\text { Duchenne muscular } \\
\text { dystrophy }\end{array}$ \\
\hline $16 \mathrm{~W} / 7 \mathrm{X} / 30^{\prime} / 30-60 \%$ & Covey et al. (Covey et al., 2001) & COPD \\
\hline $6 W / 5 X / 20^{\prime} />40 \%$ & $\begin{array}{l}\text { de Jong et al. (de Jong, van } \\
\text { Aalderen, Kraan, Koeter, \& van } \\
\text { der Schans, 2001) }\end{array}$ & Cystic fibrosis \\
\hline $6 \mathrm{~W} / 7 \mathrm{X}(2) / 15-20^{\prime} / ?$ & Liaw et al.(Liaw, et al., 2000) & SCI \\
\hline $6 \mathrm{~W} / 7 \mathrm{X}(2) / 15^{\prime} / 70 \%$ & Uijl et al. (Uijl, et al., 1999) & Tetraplegia \\
\hline $60 \mathrm{~W} / 7 \mathrm{X}(2) / 15^{\prime} / 15 \%$ & Sudo et al.(Sudo et al., 1997) & COPD \\
\hline $10 \mathrm{~W} / 6 \mathrm{X} / 30^{\prime} / 30 \%$ & Lisboa et al.(Lisboa et al., 1997) & $\begin{array}{l}\text { Chronic airflow } \\
\text { limitation }\end{array}$ \\
\hline $8 \mathrm{WW} / 7 \mathrm{X}(3) / 5-15^{\prime} / 20 \%$ & $\begin{array}{l}\text { Cahalin, Semigran, \& Dee } \\
\text { (Cahalin, Semigran, \& Dee, 1997), }\end{array}$ & $\begin{array}{l}\text { CHF (indication for } \\
\text { transplantation) }\end{array}$ \\
\hline
\end{tabular}

W: weeks; X: times per week; (2): twice a day; (3): three times a day; \%: percentage of MIP.

Chart 4 . Diversity of inspiratory training protocols.

\subsection{Effects of inspiratory muscle training on the weaning process in critically ill tracheostomized patients - Results of previous studies}

Imbalance between increased ventilatory overload and reduced ventilatory endurance is an important determinant of MV dependence. Thus, respiratory muscle weakness is nearly always present as a contributing factor for weaning failure. Even so, there is little information on the use of the respiratory muscle training program for difficult-to-wean patients (Caruso, et al., 2005; A. D. Martin, et al., 2002; U. J. Martin, et al., 2005). Although some studies recommend IMT during MV (Chang, Boots, Brown, et al., 2005; Del Rosario, et al., 1997; Sprague \& Hopkins, 2003), Chang et al. (2005) observed a post-weaning reduction in inspiratory muscle strength in patients submitted to long-term MV. 
Hawkes et al. (2007) used electromyographic analysis to examine the effect of submaximal inspiratory overload on MIP and diaphragm and intercostal muscles. Results obtained 15 minutes after the test revealed an increase in MIP ( $p=0.032)$. During MIP, an increase was recorded in the range of diaphragm $(p=0.032)$ and intercostal $(p=0.016)$ muscle action $(p=0.039)$. These data support the hypothesis of greater muscle strength after submaximal inspiratory effort or IMT, resulting in a reduction in perception of respiratory effort (dyspnea) (McConnell \& Romer, 2004; Volianitis, et al., 2001).

A.D. Martin et al. (2002) carried out a study in which IMT was performed using threshold IMT in 10 patients (tracheostomized) dependent on MV (34 \pm 33 days), in order to facilitate weaning from the ventilator by improving inspiratory muscle strength. In addition to a significant increase in strengthening workload used $(7 \pm 3 \mathrm{cmH} 2 \mathrm{O}$ for $18 \pm 7 \mathrm{cmH} 2 \mathrm{O}, \mathrm{p}<0.05)$ in threshold IMT, after $44 \pm 43$ days of IMT, 9 of 10 patients submitted to training were successfully weaned.

The effect of IMT was observed in a randomized prospective study, evidenced by reduced ventilator sensitivity and shorter weaning and reintubation time in critically ill patients (Caruso, et al., 2005). These authors observed no significant difference between training and control groups with respect to weaning time $(p=0.24)$, reintubation frequency $(p=0.39)$ and final MIP value $(p=0.34)$. However, it is important to underscore that, in addition to the small sample size, the fact that some patients did not have an ideal level of consciousness to determine MIP may have caused its underestimation. Consequently, the load applied might have been too low. This fact, along with short training time, could have influenced the final results.

Sprague \& Hopkins (2003) aimed at weaning tracheostomized MV-dependent patients by increasing inspiratory muscle strength using threshold IMT. The protocol consisted of: 6-7 days per week, once a day, 4 series of 6-8 repetitions, with a 5-10-minute rest period (under MV) between series. Training load (approximately $50 \%$ of MIP) was modified according to Borg's scale. After IMT, patients remained under spontaneous breathing via T-piece, with a gradual increase over time. Results showed a rise in training load $(9.3 \mathrm{cmH} 2 \mathrm{O}$ for 27.5 cmH2O; $195 \%)$; increase in MIP (22.0 to $54.0 \mathrm{cmH} 2 \mathrm{O}$; $140 \%)$; and successful weaning in all patients over a period of 9 to 28 days.

Frutos-Vivar et al. (2006) observed that pneumonia, as the initial trigger of AFR (with consequent intubation), is one of the primary causes of intubation. Based on this information, the study conducted by Kang et al. (2006) is very important to the present investigation, since these authors aimed to assess the relationship between inspiratory muscle strength and cough capacity, but in patients with SCI. They obtained intermediate correlation between VC and voluntary cough capacity $(\mathrm{r}=0.583 ; \mathrm{p}<0.001)$, intermediate-high between VC and MIP $(r=0.749 ; \mathrm{p}<0.001)$ and intermediate between VC and MEP $(r=0.438$; $\mathrm{p}<0.001)$; MIP also exhibited more significant correlations $(\mathrm{p}<0.001$, with intermediate to intermediate-high correlations) with peak cough flow compred to MEP ( $p<0.05$, with lowintermediate and intermediate correlations).

Another investigation, conducted in patients with spinal cord injury, underscored the importance of respiratory muscle training, increasing endurance and strength, in order to wean these individuals (Gutierrez et al., 2003). Comparative pre- and post-training data 
demonstrated a significant rise in MIP ( $p<0.001$; mean of $-18 \mathrm{cmH} 2 \mathrm{O})$, MEP $(\mathrm{p}<0.001$; mean of $21.6 \mathrm{cmH} 2 \mathrm{O})$ and $\mathrm{VC}(\mathrm{p}<0.001$; mean of $340 \mathrm{cc})$ in patients with lower lesions, favoring their weaning.

Few studies have assessed the magnitude and extent of generalized muscle weakness in patients with prolonged MV dependence. In a retrospective analysis of 49 patients submitted to whole-body rehabilitation (with strength and resistance training of upper (UULL) and lower limbs (LLLL), inspiratory muscles with threshold IMT, as well as the torso and gait), U. J. Martin et al. (2005) recorded a significant response $(\mathrm{p}<0.001)$ in functional status and inspiratory muscle, UULL and LLLL strength, in addition to a significant $(r=0.720 ; p<0.001)$ and inverse correlation between UULL strength at admission and weaning time.

Additional research, conducted in patients with no artificial airway, is also relevant for the present study (Baker et al., 2003; Mathers-Schmidt \& Brilla, 2005; Sapienza et al., 1999). Some post-extubation impairments occur in the upper airways (UAW), with only glottic edema and vocal cord lesions causing stridor. These alterations restrict air flow in the upper airways, resulting in dyspnea and eventual reintubation (Esteban, et al., 1997). Baker et al. (Baker, et al., 2003) studied in patients with upper airway limitation (glottis) resulting from bilateral vocal cord paralysis (abductors). The authors aimed to determine whether inspiratory muscle strengthening increases inspiratory muscle ability, generating greater MIP and reducing dyspnea sensation during exercise and speech. Threshold IMT was used for training, with the following protocol: load of $75 \%$ of MIP, 5 times per week, 5 series of 5 repetitions, for 5 weeks. Results revealed an increase of $47 \%$ in MIP, reduced dyspnea during exercise and speech of 2-4 points on Borg's scale and improved airway opening (glottis), visualized by endoscopy.

In a study performed with healthy individuals, nuclear magnetic resonance showed acute and chronic responses of the UAWs to ITM (How et al., 2007). Results demonstrated significant alterations in the experimental group, as follows: increase in UAW dilator muscles (genioglossus and geniohyoid) $(\mathrm{p}<0.001)$; increase in transverse section area $(p=0.025)$ and lateral diameter $(p=0.003)$ of the UAWs; increase in nasopharynx $(p<0,001)$ and laryngopharynx $(\mathrm{p}=0.031)$.

Another advantage of IMT was the reduction in central respiratory stimulus $\left(\mathrm{P}_{0.1}\right)$ (Huang et al., 2003). In this investigation, the intervention was performed in 23 apparently healthy individuals (28.8 \pm 2.3 years). The protocol used an increasing inspiratory load of $30 \%$ to $75 \%$ of MIP; 5 days a week; 4 series of 6 repetitions; for 4 weeks. The significant increase in MIP $(\mathrm{p}<0.001)$ had a significant negative correlation $(\mathrm{p}<0.01)$ with the significant reduction in $\mathrm{P}_{0.1}$ $(p<001)$. These data suggest that once $P_{0.1}$ is reduced, the occurrence of dyspnea decreases (N. Ambrosino et al., 1994; Ferrari et al., 1997).

\subsection{Effects of inspiratory muscle training on the weaning process of critically ill intubated patients - Results of a pioneering study}

Cader et al.(S. A. Cader et al., 2010) investigated elderly patients to detemine whether inspiratory muscle training improved maximal inspiratory pressure, breathing pattern and length of weaning time from mechanical ventilation. Of the 198 patients screened during the recruitment, the 67 eligible individuals were monitored daily to assess readiness to start 
weaning. Twenty of the subjects were tracheostomized, 5 died and 1 was transferred to another center before the start of weaning. The remaining 41 were randomized: 21 to the experimental group and 20 to the control group. Four participants in each group died before extubation. Three participants in the experimental group and two in the control group were tracheostomized before extubation.

Group data for all outcomes at the start of weaning and at extubation for the experimental and control groups are presented in Table 1. Maximal inspiratory pressure increased significantly more in the treatment group than in the control group (MD $7 \mathrm{cmH}_{2} 0,95 \% \mathrm{CI} 4$ to 10). The Tobin index decreased significantly more in the treatment group $(73.6 \mathrm{br} / \mathrm{min} / 1$ to $81.5 \mathrm{br} / \mathrm{min} / \mathrm{l})$ than among controls $(81.5 \mathrm{br} / \mathrm{min} / 1$ to $95.9 \mathrm{br} / \mathrm{min} / 1)$. In those who did not die or receive a tracheostomy, time to weaning was significantly shorter in the treatment group than in the control group (MD 2 days, 95\% CI 0 to 3).

Among uncensored participants, inspiratory muscle training significantly reduced the spontaneous ventilation (ie, weaning) period. Inspiratory muscle training shortened weaning time by 1.7 days ( $95 \%$ CI 0.4 to 3.0), as shown in Table 2.

\begin{tabular}{|c|c|c|c|c|c|c|c|}
\hline \multirow[t]{3}{*}{ Outcome } & \multicolumn{4}{|l|}{ Groups } & \multirow{2}{*}{\multicolumn{2}{|c|}{$\begin{array}{l}\text { Within-group } \\
\text { difference } \\
\text { Post-test minus } \\
\text { pre-test }\end{array}$}} & \multirow{3}{*}{$\begin{array}{l}\text { Between- } \\
\text { group } \\
\text { difference } \\
\begin{array}{l}\text { Post-test minus } \\
\text { pre-test }\end{array} \\
\text { Exp minus Con }\end{array}$} \\
\hline & \multicolumn{2}{|l|}{ Pre-test } & \multicolumn{2}{|l|}{ Post-test } & & & \\
\hline & $\begin{array}{l}\operatorname{Exp} \\
(\mathrm{n}=14)\end{array}$ & $\begin{array}{l}\text { Con } \\
(\mathrm{n}=14)\end{array}$ & $\begin{array}{l}\operatorname{Exp} \\
(\mathrm{n}=14)\end{array}$ & $\begin{array}{l}\text { Con } \\
(\mathrm{n}=14)\end{array}$ & Exp & Con & \\
\hline $\begin{array}{l}\mathrm{MIP} \\
\left(\mathrm{cmH}_{2} \mathrm{O}\right)\end{array}$ & $\begin{array}{l}15.1 \\
(2.6)\end{array}$ & $\begin{array}{l}15.3 \\
(2.2)\end{array}$ & $\begin{array}{l}25.0 \\
(3.9)\end{array}$ & $\begin{array}{l}17.6 \\
(1.9)\end{array}$ & $\begin{array}{l}9.9 \\
(2.5)\end{array}$ & $\begin{array}{l}2.3 \\
(2.1)\end{array}$ & $\begin{array}{l}7.6 \\
\text { (5.8 to } 9.4 \text { ) }\end{array}$ \\
\hline $\begin{array}{l}\text { TI } \\
(b r / m i n / L)\end{array}$ & $\begin{array}{l}73.6 \\
(8.8)\end{array}$ & $\begin{array}{l}81.5 \\
(6.9)\end{array}$ & $\begin{array}{l}79.7 \\
(11.2)\end{array}$ & $\begin{array}{l}95.9 \\
(12.4)\end{array}$ & $\begin{array}{l}6.1 \\
(3.6)\end{array}$ & $\begin{array}{l}14.4 \\
(9.1)\end{array}$ & $\begin{array}{l}-8.3 \\
(-13.7 \text { to }-2.9)\end{array}$ \\
\hline
\end{tabular}

$\mathrm{TI}=$ Tobin index $(\mathrm{ipm} / \mathrm{l}) ; \mathrm{MIP}=$ maximal inspiratory pressure $\left(\mathrm{cmH}_{2} \mathrm{O}\right) ;$ Exp = experimental group; Con $=$ control

Table 1. Mean (SD) outcomes for each group, mean (SD) difference within groups and mean difference $(95 \% \mathrm{CI})$ between groups.

\begin{tabular}{lllll}
\hline & \multicolumn{2}{c}{ Groups } & & $\begin{array}{l}\text { Mean inter- } \\
\text { groupdifference }\end{array}$ \\
\cline { 2 - 3 } \cline { 5 - 5 } & $\begin{array}{l}\text { Exp } \\
(\mathrm{n}=14)\end{array}$ & $\begin{array}{l}\text { Con } \\
(\mathrm{n}=14)\end{array}$ & & Exp minus Con \\
\hline Total ventilation period & $10.4(4.0)$ & $11.0(3.5)$ & & $0.6(-3.5$ to 2.4$)$ \\
Spontaneous ventilation period & $3.6(1.5)$ & $5.3(1.9)$ & & $1.7(0.4$ to 3.0) \\
\hline
\end{tabular}

Exp $=$ experimental group, Con $=$ control group

Table 2. Mean (SD) duration (days) of total ventilation and spontaneous ventilation periods among uncensored participants. 
The receiver operating characteristic curve (sensitivity and specificity) was used to evaluate weaning predictors and extubation success. Beginning with the Tobin index, the receiver operating characteristic curve reveals an area below the curve of 0.877 (SD 0.06). Sensitivity and specificity of the Tobin index was 1.00 and 0.36, respectively. Maximum inspiratory pressure was 0.86 for sensitivity and 0.72 for specificity. The area below the receiver operating characteristic curve shows a value of 0.845 (SD 0.07).

Thus, it was concluded that inspiratory muscle training in the experimental group contributed to a significant increase in maximum inspiratory pressure (between and within groups) and a reduction in the Tobin index (within groups). These are considered good weaning predictors, which is consistent with our finding that inspiratory muscle training significantly reduces the weaning period in patients who did not die or receive a tracheostomy.

\section{Conclusions}

This chapter presented an important alternative for inspiratory muscle training in critically ill patients. The technique aims at shortening weaning time and increasing extubation success rates.

IMT was found to improve some weaning predictors such as TI, MIP and MEP, favoring a reduction in weaning time. This outcome is essential in the ICU, since it decreases physiological alterations and complications from ventilator use, such as barotrauma, tracheal lesion, sarcopenia, repeated infections, scabs and surgical invasions. These findings are relevant because they contribute to shorter hospital stays and lower costs, resulting in fewer social repercussions and enhanced pre-and post-hospitalization quality of life.

Recommendations of the present study are divided into two categories: applicability and continuity.

With respect to continuity, the authors recommend that randomized controlled studies be carried out to compare IMT using threshold IMT with other interventions, such as reduced sensitivity and mechanical ventilator support pressure in intubated subjects. We further suggest that prospective studies be applied to assess the effects of training and its continued use in hospital patients, following up these individuals after discharge from the intensive therapy center (ITC) to a semi-intensive unit, infirmary or room.

In relation to the applicability of the present study, it is hoped that the knowledge acquired will be made available to physical therapists so they may intervene as early as possible, thereby avoiding future complications previously experienced in the ICU, mainly when elderly patients are involved. It is suggested that this intervention (IMT) be implemented in ITCs in order to reduce the number of tracheostomies, increase extubation sucess rates and decrease hospital stays, all of which will improve patient well-being.

\section{References}

Afessa, B., Hogans, L., \& Murphy, R. . (1999). Predicting 3-day and 7-day outcomes of weaning from mechanical ventilation. . Chest, 116, 456-461. 
Aldrich, T. K., \& Karpel, J. P. (1985). Inspiratory muscle resistive training in respiratory failure. Am Rev Respir Dis, 131(3), 461-462.

Aldrich, T. K., Karpel, J. P., Uhrlass, R. M., Sparapani, M. A., Eramo, D., \& Ferranti, R. (1989). Weaning from mechanical ventilation: adjunctive use of inspiratory muscle resistive training. Crit Care Med, 17(2), 143-147.

Aldrich, T. K., \& Uhrlass, R. M. (1987). Weaning from mechanical ventilation: successful use of modified inspiratory resistive training in muscular dystrophy. Crit Care Med, 15(3), 247-249.

Alvisi, R., Volta, C. A., Righini, E. R., Capuzzo, M., Ragazzi, R., Verri, M., . . Milic-Emili, J. (2000). Predictors of weaning outcome in chronic obstructive pulmonary disease patients. Eur Respir J, 15(4), 656-662.

Ambrosino, N. (2005). Weaning and respiratory muscle dysfunction: the egg-chicken dilemma. Chest, 128(2), 481-483.

Ambrosino, N., Opasich, C., Crotti, P., Cobelli, F., Tavazzi, L., \& Rampulla, C. (1994). Breathing pattern, ventilatory drive and respiratory muscle strength in patients with chronic heart failure. Eur Respir J, 7(1), 17-22.

Angus, D., Ishizaka, A., Matthay, M., Lemaire, F., Macnee, W., \& Abraham, E. (2005). Critical care in AJRCCM 2004. Am J Respir Crit Care Med, 171(6), 537-544.

Anzueto, A., Peters, J. I., Tobin, M. J., de los Santos, R., Seidenfeld, J. J., Moore, G., . . . Coalson, J. J. (1997). Effects of prolonged controlled mechanical ventilation on diaphragmatic function in healthy adult baboons. Crit Care Med, 25(7), 1187-1190.

Appendini, L., Purro, A., Patessio, A., Zanaboni, S., Carone, M., Spada, E., . . . Rossi, A. (1996). Partitioning of inspiratory muscle workload and pressure assistance in ventilator-dependent COPD patients. Am J Respir Crit Care Med, 154(5), 1301-1309.

Baker, S E, Sapienza, C M, Martin, D, Davenport, P. D., Hoffman-Ruddy, B, \& Woodson, G. (2003). Inspiratory Pressure Threshold training for upper airway limitation: a case of bilateral abductor vocal fold paralysis. Journal of Voice, 17(3), 384-394.

Bardsley, P. A., Bentley, S., Hall, H. S., Singh, S. J., Evans, D. H., \& Morgan, M. D. (1993). Measurement of inspiratory muscle performance with incremental threshold loading: a comparison of two techniques. Thorax, 48(4), 354-359.

Belman, M. J. (1981). Respiratory failure treated by ventilatory muscle training (VMT). A report of two cases. Eur J Respir Dis, 62(6), 391-395.

Brancaleone, P., Perez, T., Robin, S., Neviere, R., \& Wallaert, B. (2004). Clinical impact of inspiratory muscle impairment in sarcoidosis. Sarcoidosis Vasc Diffuse Lung Dis, 21(3), 219-227.

Bruera, E., Schmitz, B., Pither, J., Neumann, C. M., \& Hanson, J. (2000). The frequency and correlates of dyspnea in patients with advanced cancer. J Pain Symptom Manage, 19(5), 357-362.

Bruton, A. (2002). A pilot study to investigate any relationship between sustained maximal inspiratory pressure and extubation outcome. Heart Lung, 31(2), 141-149.

Bruton, A. A., Conway, J. H., \& Holgate, S. T. (2002). Inspiratory muscle dysfunction after prolonged periods of mechanical ventilation. Physiotherapy, 88(3), 131-137.

Butler, R., Keenan, S. P., Inman, K. J., Sibbald, W. J., \& Block, G. (1999). Is there a preferred technique for weaning the difficult-to-wean patient? A systematic review of the literature. Crit Care Med, 27(11), 2331-2336. 
Cader, S A. (2006). Força Muscular Respiratória: como aferi-la e fortalecê-la? Fitness e Performance Journal, 5(1), 57.

Cader, S A, Silva, E B, Vale, R G S, Bacelar, S C, \& Dantas, E H M. (2007). Efeito do treino dos músculos inspiratórios sobre a pressão inspiratória máxima e a autonomia funcional de idosos asilados. Motricidade, 3(1), 279-288.

Cader, S. A., Vale, R. G., Castro, J. C., Bacelar, S. C., Biehl, C., Gomes, M. C., . . Dantas, E. H. (2010). Inspiratory muscle training improves maximal inspiratory pressure and may assist weaning in older intubated patients: a randomised trial. [Randomized Controlled Trial]. Journal of physiotherapy, 56(3), 171-177.

Cahalin, L. P., Semigran, M. J., \& Dee, G. W. (1997). Inspiratory muscle training in patients with chronic heart failure awaiting cardiac transplantation: results of a pilot clinical trial. Phys Ther, 77(8), 830-838.

Campbell, E. J., Gandevia, S. C., Killian, K. J., Mahutte, C. K., \& Rigg, J. R. (1980). Changes in the perception of inspiratory resistive loads during partial curarization. J Physiol, 309, 93-100.

Capdevila, X. J., Perrigault, P. F., Perey, P. J., Roustan, J. P., \& d'Athis, F. (1995). Occlusion pressure and its ratio to maximum inspiratory pressure are useful predictors for successful extubation following T-piece weaning trial. Chest, 108(2), 482-489.

Capdevila, X., Perrigault, P. F., Ramonatxo, M., Roustan, J. P., Peray, P., d'Athis, F., \& Prefaut, C. (1998). Changes in breathing pattern and respiratory muscle performance parameters during difficult weaning. Crit Care Med, 26(1), 79-87.

Carolan, B., \& Cafarelli, E. (1992). Adaptations in coactivation after isometric resistance training. J Appl Physiol, 73(3), 911-917.

Caruso, P., Denari, S. D., Ruiz, S. A., Bernal, K. G., Manfrin, G. M., Friedrich, C., \& Deheinzelin, D. (2005). Inspiratory muscle training is ineffective in mechanically ventilated critically ill patients. Clinics, 60(6), 479-484.

Caruso, P., Friedrich, C., Denari, S. D., Ruiz, S. A., \& Deheinzelin, D. (1999). The unidirectional valve is the best method to determine maximal inspiratory pressure during weaning. Chest, 115(4), 1096-1101.

Chang, A. T., Boots, R. J., Brown, M. G., Paratz, J., \& Hodges, P. W. (2005). Reduced inspiratory muscle endurance following successful weaning from prolonged mechanical ventilation. Chest, 128(2), 553-559.

Chang, A. T., Boots, R. J., Henderson, R., Paratz, J. D., \& Hodges, P. W. (2005). Case report: inspiratory muscle training in chronic critically ill patients--a report of two cases. Physiother Res Int, 10(4), 222-226.

Chao, D. C., \& Scheinhorn, D. J. (1998). Weaning from mechanical ventilation. Crit Care Clin, 14(4), 799-817, viii.

Chatham, K. (2000). Individualised fixed load inspiratory muscle training responses in a patient with severe restrictive lung disease and an élite sportsman. Physiotherapy, 86(1), 28-31.

Chatila, W., Jacob, B., Guaglionone, D., \& Manthous, C. A. (1996). The unassisted respiratory rate-tidal volume ratio accurately predicts weaning outcome. Am J Med, 101(1), 6167. 
Chelluri, L., Rotondi, A., Sirio, C., \& al., et. (2002). 2-Month mortality and functional status of critically ill adult patients receiving prolonged mechanical ventilation. Chest, 121, 549-558.

Cimen, O. B., Ulubas, B., Sahin, G., Calikoglu, M., Bagis, S., \& Erdogan, C. (2003). Pulmonary function tests, respiratory muscle strength, and endurance of patients with osteoporosis. South Med J, 96(5), 423-426.

Clanton, T, Calvery, P M, \& Celli, B R. (2002). Tests of respiratory muscle endurance. American Journal of Respiratory and Critical Care Medicine, 166(4), 559-570.

Cluzel, P., Similowski, T., Chartrand-Lefebvre, C., Zelter, M., Derenne, J. P., \& Grenier, P. A. (2000). Diaphragm and chest wall: assessment of the inspiratory pump with MR imaging-preliminary observations. Radiology, 215(2), 574-583.

Conti, G., Montini, L., Pennisi, M. A., Cavaliere, F., Arcangeli, A., Bocci, M. G., . . . Antonelli, M. (2004). A prospective, blinded evaluation of indexes proposed to predict weaning from mechanical ventilation. Intensive Care Med, 30(5), 830-836.

Covey, M. K., Larson, J. L., Wirtz, S. E., Berry, J. K., Pogue, N. J., Alex, C. G., \& Patel, M. (2001). High-intensity inspiratory muscle training in patients with chronic obstructive pulmonary disease and severely reduced function. J Cardiopulm Rehabil, 21(4), 231-240.

de Freitas Fregonezi, G. A., Resqueti, V. R., \& Casan, P. (2006). [Domiciliary respiratory muscle training in myotonic dystrophy]. Arch Bronconeumol, 42(11), 605-607.

de Jong, W., van Aalderen, W. M., Kraan, J., Koeter, G. H., \& van der Schans, C. P. (2001). Inspiratory muscle training in patients with cystic fibrosis. Respir Med, 95(1), 31-36.

Del Rosario, N., Sassoon, C. S., Chetty, K. G., Gruer, S. E., \& Mahutte, C. K. (1997). Breathing pattern during acute respiratory failure and recovery. Eur Respir J, 10(11), 25602565.

Dojat, M., Harf, A., Touchard, D., Laforest, M., Lemaire, F., \& Brochard, L. (1996). Evaluation of a knowledge-based system providing ventilatory management and decision for extubation. Am J Respir Crit Care Med, 153(3), 997-1004.

Douglas, S.L., Daly, B.J., \& Gordon, N. (2002). Survival and quality of life: short-term versus long-term ventilator patients. Critical Care Medicine, 30, 2655-2662.

el-Khatib, M. F., Baumeister, B., Smith, P. G., Chatburn, R. L., \& Blumer, J. L. (1996). Inspiratory pressure/maximal inspiratory pressure: does it predict successful extubation in critically ill infants and children? Intensive Care Med, 22(3), 264-268.

Enright, S., Chatham, K., Ionescu, A. A., Unnithan, V. B., \& Shale, D. J. (2004). Inspiratory muscle training improves lung function and exercise capacity in adults with cystic fibrosis. Chest, 126(2), 405-411.

Epstein, C. D., El-Mokadem, N., \& Peerless, J. R. (2002). Weaning older patients from longterm mechanical ventilation: a pilot study. Am J Crit Care, 11(4), 369-377.

Epstein, S. K. (1995). Etiology of extubation failure and the predictive value of the rapid shallow breathing index. Am J Respir Crit Care Med, 152(2), 545-549.

Epstein, S. K. (2002). Decision to extubate. Intensive Care Med, 28(5), 535-546.

Epstein, S. K., \& Ciubotaru, R. L. (1996). Influence of gender and endotracheal tube size on preextubation breathing pattern. Am J Respir Crit Care Med, 154(6 Pt 1), 1647-1652.

Esteban, A., Alia, I., Gordo, F., de Pablo, R., Suarez, J., Gonzalez, G., \& Blanco, J. (2000). Prospective randomized trial comparing pressure-controlled ventilation and 
volume-controlled ventilation in ARDS. For the Spanish Lung Failure Collaborative Group. Chest, 117(6), 1690-1696.

Esteban, A., Alia, I., Gordo, F., Fernandez, R., Solsona, J. F., Vallverdu, I., . . Goldwasser, R. S. (1997). Extubation outcome after spontaneous breathing trials with T-tube or pressure support ventilation. The Spanish Lung Failure Collaborative Group. Am J Respir Crit Care Med, 156(2 Pt 1), 459-465.

Esteban, A., Anzueto, A., Alia, I., Gordo, F., Apezteguia, C., Palizas, F., . . . Tobin, M. J. (2000). How is mechanical ventilation employed in the intensive care unit? An international utilization review. Am J Respir Crit Care Med, 161(5), 1450-1458.

Esteban, A., Frutos, F., Tobin, M. J., Alia, I., Solsona, J. F., Valverdu, I., . . . et al. (1995). A comparison of four methods of weaning patients from mechanical ventilation. Spanish Lung Failure Collaborative Group. N Engl J Med, 332(6), 345-350.

Ezingeard, E., Diconne, E., Guyomarc'h, S., Venet, C., Page, D., Gery, P., . . Zeni, F. (2006). Weaning from mechanical ventilation with pressure support in patients failing a Ttube trial of spontaneous breathing. Intensive Care Med, 32(1), 165-169.

Farias, J. A., Alia, I., Retta, A., Olazarri, F., Fernandez, A., Esteban, A., . . Sheehan, G. (2002). An evaluation of extubation failure predictors in mechanically ventilated infants and children. Intensive Care Med, 28(6), 752-757.

Ferrari, K., Goti, P., Duranti, R., Iandelli, I., Misuri, G., Mancini, M., . . . Scano, G. (1997). Breathlessness and control of breathing in patients with COPD. Monaldi Arch Chest Dis, 52(1), 18-23.

Fregonezi, G. A., Resqueti, V. R., Guell, R., Pradas, J., \& Casan, P. (2005). Effects of 8-week, interval-based inspiratory muscle training and breathing retraining in patients with generalized myasthenia gravis. Chest, 128(3), 1524-1530.

Frutos-Vivar, F., Ferguson, N. D., Esteban, A., Epstein, S. K., Arabi, Y., Apezteguia, C., . . . Anzueto, A. (2006). Risk factors for extubation failure in patients following a successful spontaneous breathing trial. Chest, 130(6), 1664-1671.

Gandia, F, \& Blanco, J. (1992). Evaluation of indexes predicting the outcome of ventilator weaning and value of adding supplemental inspiratory load. Intensive Care Med, 18, 327.

Gayan-Ramirez, G., \& Decramer, M. (2002). Effects of mechanical ventilation on diaphragm function and biology. Eur Respir J, 20(6), 1579-1586.

Goldstone, J. (2002). The pulmonary physician in critical care. 10: difficult weaning. Thorax, 57(11), 986-991.

Goldwasser, R.S. (1998). Estudo da eficácia de dois diferentes testes de tolerância de interrupção da ventilação mecânica para predizer o êxito da extubação em pacientes portadores de doença pulmonar obstrutiva crônica. Tese de Mestrado., Universidade Federal do Rio de Janeiro., Rio de Janeiro.

Green, M, Road, J, Sieck, G C, \& Similowski, T. (2002). Tests of respiratory muscle strength. American Journal of Respiratory and Critical Care Medicine, 166(4), 528-547.

Gutierrez, C. J., Harrow, J., \& Haines, F. (2003). Using an evidence-based protocol to guide rehabilitation and weaning of ventilator-dependent cervical spinal cord injury patients. J Rehabil Res Dev, 40(5 Suppl 2), 99-110. 
Haberthur, C., Mols, G., Elsasser, S., Bingisser, R., Stocker, R., \& Guttmann, J. (2002). Extubation after breathing trials with automatic tube compensation, T-tube, or pressure support ventilation. Acta Anaesthesiol Scand, 46(8), 973-979.

Hawkes, E. Z., Nowicky, A. V., \& McConnell, A. K. (2007). Diaphragm and intercostal surface EMG and muscle performance after acute inspiratory muscle loading. Respir Physiol Neurobiol, 155(3), 213-219.

Hoo, G.W.S., \& Park, L. (2002). Variations in the measurement of weaning parameters. Chest, 121, 1947-1955.

How, S C, McConnell, A K, Taylor, B J, \& Romer, L M. (2007). Acute and chronic responses of the upper airway to inspiratory loading in hellthy awake humans: An MRI study. Respiratory Physiology \& Neurobiology, 157, 270-280.

Huang, C H, Martin, A D, \& Davenport, P. W. (2003). Effect of inspiratory muscle strength training on inspiratory motor drive and RREP early peak components. J Appl Physiol, 94, 462-468.

Inbar, O., Weiner, P., Azgad, Y., Rotstein, A., \& Weinstein, Y. (2000). Specific inspiratory muscle training in well-trained endurance athletes. Med Sci Sports Exerc, 32(7), 12331237.

Jaeger, R. J., Turba, R. M., Yarkony, G. M., \& Roth, E. J. (1993). Cough in spinal cord injured patients: comparison of three methods to produce cough. Arch Phys Med Rehabil, 74(12), 1358-1361.

Johnson, P. H., Cowley, A. J., \& Kinnear, W. J. (1996). Evaluation of the THRESHOLD trainer for inspiratory muscle endurance training: comparison with the weighted plunger method. Eur Respir J, 9(12), 2681-2684.

Kang, S. W., Shin, J. C., Park, C. I., Moon, J. H., Rha, D. W., \& Cho, D. H. (2006). Relationship between inspiratory muscle strength and cough capacity in cervical spinal cord injured patients. Spinal Cord, 44(4), 242-248.

Khamiees, M., Raju, P., DeGirolamo, A., Amoateng-Adjepong, Y., \& Manthous, C. A. (2001). Predictors of extubation outcome in patients who have successfully completed a spontaneous breathing trial. Chest, 120(4), 1262-1270.

Klefbeck, B., \& Hamrah Nedjad, J. (2003). Effect of inspiratory muscle training in patients with multiple sclerosis. Arch Phys Med Rehabil, 84(7), 994-999.

Krieger, B. P., Isber, J., Breitenbucher, A., Throop, G., \& Ershowsky, P. (1997). Serial measurements of the rapid-shallow-breathing index as a predictor of weaning outcome in elderly medical patients. Chest, 112(4), 1029-1034.

Kuhlen, R., Max, M., Dembinski, R., Terbeck, S., Jurgens, E., \& Rossaint, R. (2003). Breathing pattern and workload during automatic tube compensation, pressure support and T-piece trials in weaning patients. Eur J Anaesthesiol, 20(1), 10-16.

Laoutaris, I., Dritsas, A., Brown, M. D., Manginas, A., Alivizatos, P. A., \& Cokkinos, D. V. (2004). Inspiratory muscle training using an incremental endurance test alleviates dyspnea and improves functional status in patients with chronic heart failure. Eur J Cardiovasc Prev Rehabil, 11(6), 489-496.

Larsson, L., Li, X., Edstrom, L., Eriksson, L. I., Zackrisson, H., Argentini, C., \& Schiaffino, S. (2000). Acute quadriplegia and loss of muscle myosin in patients treated with nondepolarizing neuromuscular blocking agents and corticosteroids: mechanisms at the cellular and molecular levels. Crit Care Med, 28(1), 34-45. 
Lee, K H, Hui, K P, \& Chang, T. (1994). Rapid shallow breathing did not predict extubation outcome. Chest, 105, 540.

Leitch, E. A., Moran, J. L., \& Grealy, B. (1996). Weaning and extubation in the intensive care unit. Clinical or index-driven approach? Intensive Care Med, 22(8), 752-759.

Leung, P., Jubran, A., \& Tobin, M. J. (1997). Comparison of assisted ventilator modes on triggering, patient effort, and dyspnea. Am J Respir Crit Care Med, 155(6), 1940-1948.

Li, Y., He, G., \& Chen, R. (2000). [Clinical study of weaning predictors in COPD patients with prolonged mechanical ventilation]. Zhonghua Jie He He Hu Xi Za Zhi, 23(4), 217-220.

Liaw, M. Y., Lin, M. C., Cheng, P. T., Wong, M. K., \& Tang, F. T. (2000). Resistive inspiratory muscle training: its effectiveness in patients with acute complete cervical cord injury. Arch Phys Med Rehabil, 81(6), 752-756.

Lisboa, G., Villafranca, C., Leiva, A., Cruz, E., Pertuze, J, \& Borzone, G. (1997). Inspiratory muscle training in chronic airflow limitation: effect on exercise performance. Eur Respir J, 10(3), 537-542.

MacIntyre, N. R., Cook, D. J., Ely, E. W., Jr., Epstein, S. K., Fink, J. B., Heffner, J. E., . . . Scheinhorn, D. J. (2001). Evidence-based guidelines for weaning and discontinuing ventilatory support: a collective task force facilitated by the American College of Chest Physicians; the American Association for Respiratory Care; and the American College of Critical Care Medicine. Chest, 120(6 Suppl), 375S-395S.

Manthous, C. A., Schmidt, G. A., \& Hall, J. B. (1998). Liberation from mechanical ventilation: a decade of progress. Chest, 114(3), 886-901.

Marini, J J, Smith, T C, \& Lamb, V. (1986). Estimation of inspiratory muscle strength in mechanically ventilated patients: The measurement of maximal inspiratory pressure. Journal of Critical Care, 1(1), 32-38.

Martin, A. D., Davenport, P. D., Franceschi, A. C., \& Harman, E. (2002). Use of inspiratory muscle strength training to facilitate ventilator weaning: a series of 10 consecutive patients. Chest, 122(1), 192-196.

Martin, U. J., Hincapie, L., Nimchuk, M., Gaughan, J., \& Criner, G. J. (2005). Impact of whole-body rehabilitation in patients receiving chronic mechanical ventilation. Crit Care Med, 33(10), 2259-2265.

Mathers-Schmidt, B. A., \& Brilla, L. R. (2005). Inspiratory muscle training in exerciseinduced paradoxical vocal fold motion. J Voice, 19(4), 635-644.

Matic, I., Danic, D., Majeric-Kogler, V., Jurjevic, M., Mirkovic, I., \& Mrzljak Vucinic, N. (2007). Chronic obstructive pulmonary disease and weaning of difficult-to-wean patients from mechanical ventilation: randomized prospective study. Croat Med J, 48(1), 51-58.

McComas, A. J. (1994). Human neuromuscular adaptations that accompany changes in activity. Med Sci Sports Exerc, 26(12), 1498-1509.

McConnell, A. K., \& Romer, L. M. (2004). Dyspnoea in health and obstructive pulmonary disease : the role of respiratory muscle function and training. Sports Med, 34(2), 117132.

Meade, M., Guyatt, G., Cook, D., Griffith, L., Sinuff, T., Kergl, C., . . E Epstein, S. (2001). Predicting success in weaning from mechanical ventilation. Chest, 120(6 Suppl), 400S-424S. 
Mergoni, M., Costa, A., Primavera, S., Salvadori, A., Saccani, A., \& Zuccoli, P. (1996). [Assessment of various new predictive parameters of the outcome of mechanical ventilation weaning]. Minerva Anestesiol, 62(5), 153-164.

Milner-Brown, H. S., Stein, R. B., \& Lee, R. G. (1975). Synchronization of human motor units: possible roles of exercise and supraspinal reflexes. Electroencephalogr Clin Neurophysiol, 38(3), 245-254.

Nield, M. A. (1999). Inspiratory muscle training protocol using a pressure threshold device: effect on dyspnea in chronic obstructive pulmonary disease. Arch Phys Med Rehabil, 80(1), 100-102.

Noizet, O., Leclerc, F., Sadik, A., Grandbastien, B., Riou, Y., Dorkenoo, A., . . L Leteurtre, S. (2005). Does taking endurance into account improve the prediction of weaning outcome in mechanically ventilated children? Crit Care, 9(6), R798-807.

Powers, S. K., Shanely, R. A., Coombes, J. S., Koesterer, T. J., McKenzie, M., Van Gammeren, D., . . Dodd, S. L. (2002). Mechanical ventilation results in progressive contractile dysfunction in the diaphragm. J Appl Physiol, 92(5), 1851-1858.

Ramirez-Sarmiento, A., Orozco-Levi, M., Guell, R., Barreiro, E., Hernandez, N., Mota, S., . . . Gea, J. (2002). Inspiratory muscle training in patients with chronic obstructive pulmonary disease: structural adaptation and physiologic outcomes. Am J Respir Crit Care Med, 166(11), 1491-1497.

Robriquet, L., Georges, H., Leroy, O., Devos, P., D'Escrivan, T., \& Guery, B. (2006). Predictors of extubation failure in patients with chronic obstructive pulmonary disease. J Crit Care, 21(2), 185-190.

Rose, L., \& Ed, A. (2006). Advanced modes of mechanical ventilation: implications for practice. AACN Adv Crit Care, 17(2), 145-158; quiz 159-160.

Rothaar, R. C., \& Epstein, S. K. (2003). Extubation failure: magnitude of the problem, impact on outcomes, and prevention. Curr Opin Crit Care, 9(1), 59-66.

Salam, A., Tilluckdharry, L., Amoateng-Adjepong, Y., \& Manthous, C. A. (2004). Neurologic status, cough, secretions and extubation outcomes. Intensive Care Med, 30(7), 13341339.

Sale, D. G. (1988). Neural adaptation to resistance training. Med Sci Sports Exerc, 20(5 Suppl), S135-145.

Sanchez Riera, H., Montemayor Rubio, T., Ortega Ruiz, F., Cejudo Ramos, P., Del Castillo Otero, D., Elias Hernandez, T., \& Castillo Gomez, J. (2001). Inspiratory muscle training in patients with COPD: effect on dyspnea, exercise performance, and quality of life. Chest, 120(3), 748-756.

Sapienza, C. M., Brown, J., Martin, D., \& Davenport, P. (1999). Inspiratory pressure threshold training for glottal airway limitation in laryngeal papilloma. J Voice, 13(3), 382-388.

Sassoon, C. S., Caiozzo, V. J., Manka, A., \& Sieck, G. C. (2002). Altered diaphragm contractile properties with controlled mechanical ventilation. J Appl Physiol, 92(6), 2585-2595.

Scheinhorn, D. J., Chao, D. C., \& Stearn-Hassenpflug, M. (2000). Approach to patients with long-term weaning failure. Respir Care Clin N Am, 6(3), 437-461; vi.

Spitzer, A. R., Giancarlo, T., Maher, L., Awerbuch, G., \& Bowles, A. (1992). Neuromuscular causes of prolonged ventilator dependency. Muscle Nerve, 15(6), 682-686. 
Sprague, S S, \& Hopkins, P D. (2003). Use os inspiratory strength training to wean six patients who were ventilator-dependent. Physical Therapy, 83(2), 171-181.

Stroetz, R. W., \& Hubmayr, R. D. (1995). Tidal volume maintenance during weaning with pressure support. Am J Respir Crit Care Med, 152(3), 1034-1040.

Sturdy, G., Hillman, D., Green, D., Jenkins, S., Cecins, N., \& Eastwood, P. (2003). Feasibility of high-intensity, interval-based respiratory muscle training in COPD. Chest, 123(1), 142-150.

Sudo, E., Ohga, E., Matsuse, T., Teramoto, S., Nagase, T., Katayama, H., . . Ouchi, Y. (1997). [Duration of effect of pulmonary rehabilitation in elderly patients with chronic obstructive pulmonary disease]. Nippon Ronen Igakkai Zasshi, 34(9), 739-742.

Tobin, M. J. (2001). Advances in mechanical ventilation. N Engl J Med, 344(26), 1986-1996.

Tobin, M. J., Jubran, A., \& Laghi, F. (2001). Patient-ventilator interaction. Am J Respir Crit Care Med, 163(5), 1059-1063.

Topin, N., Matecki, S., Le Bris, S., Rivier, F., Echenne, B., Prefaut, C., \& Ramonatxo, M. (2002). Dose-dependent effect of individualized respiratory muscle training in children with Duchenne muscular dystrophy. Neuromuscul Disord, 12(6), 576-583.

Uijl, S G, Houtman, S, Folgering, H T M, \& Hopman, M T E. (1999). Training of the respiratory muscles in individuals with tetraplegia. Spinal Cord, 37(8), 575-579.

Vallverdu, I., Calaf, N., Subirana, M., Net, A., Benito, S., \& Mancebo, J. (1998). Clinical characteristics, respiratory functional parameters, and outcome of a two-hour Tpiece trial in patients weaning from mechanical ventilation. Am J Respir Crit Care Med, 158(6), 1855-1862.

van der Esch, M., van 't Hul, A. J., Heijmans, M., \& Dekker, J. (2004). Respiratory muscle performance as a possible determinant of exercise capacity in patients with ankylosing spondylitis. Aust J Physiother, 50(1), 41-45.

Vassilakopoulos, T., \& Petrof, B. J. (2004). Ventilator-induced diaphragmatic dysfunction. Am J Respir Crit Care Med, 169(3), 336-341.

Venkataraman, S T, Khan, N, \& Brown, A. (2000). Validation of predictors of extubation success and failure in mechanically ventilated infants and children. Crit Care Med, 28(8), 2991-2996.

Venkataraman, S. T., Khan, N., \& Brown, A. (2000). Validation of predictors of extubation success and failure in mechanically ventilated infants and children. Crit Care Med, 28(8), 2991-2996.

Volianitis, S., McConnell, A. K., Koutedakis, Y., \& Jones, D. A. (2001). Specific respiratory warm-up improves rowing performance and exertional dyspnea. Med Sci Sports Exerc, 33(7), 1189-1193.

Weiner, P., Magadle, R., Beckerman, M., \& Berar-Yanay, N. (2002). The relationship among inspiratory muscle strength, the perception of dyspnea and inhaled beta2-agonist use in patients with asthma. Can Respir J, 9(5), 307-312.

Yang, K. L. (1993). Inspiratory pressure/maximal inspiratory pressure ratio: a predictive index of weaning outcome. Intensive Care Med, 19(4), 204-208.

Yang, K. L., \& Tobin, M. J. (1991). A prospective study of indexes predicting the outcome of trials of weaning from mechanical ventilation. N Engl J Med, 324(21), 1445-1450. 
Yue, G., \& Cole, K. J. (1992). Strength increases from the motor program: comparison of training with maximal voluntary and imagined muscle contractions. J Neurophysiol, 67(5), 1114-1123. 


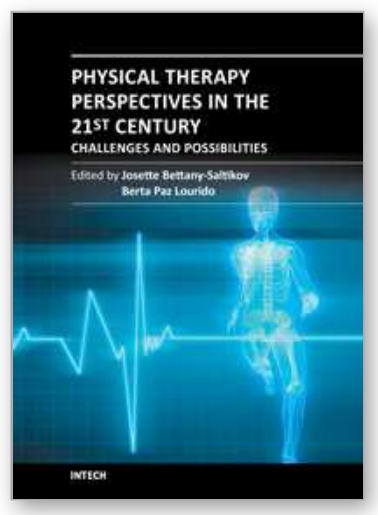

\section{Physical Therapy Perspectives in the 21st Century - Challenges and Possibilities}

Edited by Dr. Josette Bettany-Saltikov

ISBN 978-953-51-0459-9

Hard cover, 386 pages

Publisher InTech

Published online 05, April, 2012

Published in print edition April, 2012

This book contains new information on physical therapy research and clinical approaches that are being undertaken into numerous medical conditions; biomechanical and musculoskeletal conditions as well as the effects of psychological factors, body awareness and relaxation techniques; specific and specialist exercises for the treatment of scoliosis and spinal deformities in infants and adolescents; new thermal agents are being introduced and different types of physical therapy interventions are being introduced for the elderly both in the home and clinical setting. Additionally research into physical therapy interventions for patients with respiratory, cardiovascular disorders and stroke is being undertaken and new concepts of wheelchair design are being implemented.

\section{How to reference}

In order to correctly reference this scholarly work, feel free to copy and paste the following:

Samaria Cader, Rodrigo Vale and Estelio Dantas (2012). Effect of Inspiratory Muscle Training on Weaning Success in Critically III Intubated Patients, Physical Therapy Perspectives in the 21st Century - Challenges and Possibilities, Dr. Josette Bettany-Saltikov (Ed.), ISBN: 978-953-51-0459-9, InTech, Available from: http://www.intechopen.com/books/physical-therapy-perspectives-in-the-21st-century-challenges-andpossibilities/effect-of-inspiratory-muscle-training-on-weaning-success-in-critically-ill-intubated-patients

\section{INTECH}

open science | open minds

\author{
InTech Europe \\ University Campus STeP Ri \\ Slavka Krautzeka 83/A \\ 51000 Rijeka, Croatia \\ Phone: +385 (51) 770447 \\ Fax: +385 (51) 686166 \\ www.intechopen.com
}

\author{
InTech China \\ Unit 405, Office Block, Hotel Equatorial Shanghai \\ No.65, Yan An Road (West), Shanghai, 200040, China \\ 中国上海市延安西路65号上海国际贵都大饭店办公楼 405 单元 \\ Phone: +86-21-62489820 \\ Fax: +86-21-62489821
}


(C) 2012 The Author(s). Licensee IntechOpen. This is an open access article distributed under the terms of the Creative Commons Attribution 3.0 License, which permits unrestricted use, distribution, and reproduction in any medium, provided the original work is properly cited. 